\title{
Predictive factors of the long term outcome in gastro- oesophageal reflux disease: six year follow up of 107 patients
}

Elbio Kuster, Emilio Ros, Victor Toledo-Pimentel, Amadeo Pujol, Josep M Bordas, Luis Grande, Cristóbal Pera

\begin{abstract}
There is little information concerning the long term outcome of patients with gastrooesophageal reflux disease (GORD). Thus 109 patients with reflux symptoms ( 33 with erosive oesophagitis) with a diagnosis of GORD after clinical evaluation and oesophageal testing were studied. All patients were treated with a stepwise approach: (a) lifestyle changes were suggested aimed at reducing reflux and antacids and the prokinetic agent domperidone were prescribed; (b) $\mathrm{H}_{2}$ blockers were added after two months when symptoms persisted; (c) anti-reflux surgery was indicated when there was no response to $(b)$. Treatment was adjusted to maintain clinical remission during follow up. Long term treatment need was defined as minor when conservative measures sufficed for proper control, and as major if daily $\mathrm{H}_{2}$ blockers or surgery were required. The results showed that one third of the patients each had initial therapeutic need $(a)$, $(b)$, and (c). Of 103 patients available for follow up at three years and 89 at six years, respective therapeutic needs were minor in $52 \%$ and $55 \%$ and major in $48 \%$ and $45 \%$. Eighty per cent of patients in $(a), 67 \%$ in $(b)$, and $17 \%$ in $(c)$ required only conservative measures at six years. A decreasing lower oesophageal sphincter pressure $(\mathrm{p}<\mathbf{0 . 0 0 1})$, radiological reflux $(p=0.028)$, and erosive oesophagitis $(p=0.031)$, but not initial clinical scores, were independent predictors of major therapeutic need as shown by multivariate analysis. The long term outcome of GORD is better than previously perceived.

(Gut 1994; 35: 8-14)
\end{abstract}

Gastro-oesophageal reflux disease (GORD) is a common ailment. A cross sectional survey of presumably healthy people in the United States has found that $10 \%$ experience heartburn daily and up to $40 \%$ have it at least once a month. Indeed, most otherwise healthy heavy consumers of antacids have reflux disease. ${ }^{2}$

Gastro-esophageal reflux disease is a chronic disease that requires long term management in nearly all patients. The conventional medical treatment begins with modifications of lifestyle that are aimed at reducing the reflux of gastric contents into the oesophagus, such as dietary, alcohol, drug, and tobacco restriction, and elevation of the bedhead; such measures, together with appropriate antacid use, are usually effective for patients with clinically mild GORD, whereas patients with more frequent or severe reflux symptoms often require some form of acid suppressive medication with or without addition of gastric prokinetic agents. ${ }^{3}$ Antireflux surgery is a good alternative treatment for patients who do not respond well to medical treatment. ${ }^{4}$

About one third of the patients with heartburn who seek medical care have endoscopic evidence of oesophagitis, ${ }^{5}$ and therapeutic studies of GORD have been limited primarily to short term observations of the effects of single drugs in this subset of patients, with little or no emphasis on modifications of lifestyle. ${ }^{6}$ Recent clinical trials in patients with oesophagitis suggest that most patients relapse quickly when treatment is interrupted after healing ${ }^{7-10}$; however, a bias toward more severe cases to enter such trials cannot be discounted. There is little information about the long term clinical course of patients with peptic oesophagitis after diagnosis," and even less on patients with GORD but no oesophagitis.

The present study was carried out in a consecutive series of outpatients referred to a gastroenterology clinic who sought medical care because of reflux symptoms and had confirmed GORD, with and without oesophagitis. The patients were submitted initially to a stepwise therapeutic regimen until clinical remission and were subsequently given maintenance treatment sufficient for them to feel satisfied. They were then followed up for up to six years. Our aims were to devise a rational therapeutic approach to GORD and to assess the existence of predictive factors of the long term outcome. The information gathered in the study provides a comprehensive evaluation of the efficacy of prolonged treatment in GORD.

\section{Patients and methods}

PATIENTS

One hundred and thirty two consecutive outpatients who had reflux symptoms (heartburn, or acid regurgitation, or both) as their main complaint were prospectively evaluated during a 
five year period (December 1979 to January 1985) at a university affiliated gastroenterology clinic that receives referrals from community practitioners and specialists. Patients were accepted if they had had no treatment with $\mathrm{H}_{2}$ blockers for at least two months. There were 67 women and 65 men, with a mean age of 48 (range, 19-79) years. The main duration of symptoms was 11 (range, 1-50) years. Patients with peptic ulcer, prior gastric or oesophageal surgery, or any medical condition that could cause or aggravate reflux (scleroderma, alcoholism) were excluded from the study.

\section{STUDY PROTOCOL}

At the initial evaluation a composite clinical score was constructed for each patient that took into account the frequency and severity of heartburn, regurgitation, and dysphagia. Other clinical features such as non-cardiac chest pain and respiratory symptoms were also considered. All patients were offered diagnostic testing with barium swallow, fibreoptic endoscopy with pinch oesophageal biopsies, oesophageal motility studies, and either standard acid reflux test without $\mathrm{HCl}$ loading (during the first four years of patient acquisition) or 24 hour oesophageal $\mathrm{pH}$ monitoring (during the last year).

\section{THERAPEUTIC APPROACH}

After baseline examination, the patients were given detailed dietary, alcohol, smoking, drug, and postural advice. ${ }^{12-14}$ Besides efforts at modification of lifestyle, all patients were treated with single doses of an oral prokinetic drug $(10 \mathrm{mg}$ domperidone) before meals in addition to $15 \mathrm{ml}$ of a liquid antacid preparation (aluminium hydroxide/magnesium hydroxide mixture with an in vitro neutralising capacity of $4.0 \mathrm{mmol} \mathrm{H}^{+} /$ $\mathrm{ml}$ ) six times a day, one hour, and three hours after meals, for at least two months. Specific instructions were given to regularly take the prescribed doses of antacid even in the absence of symptoms and to use additional antacid as needed for symptom relief. After two months, patients with unimproved symptoms were treated additionally with standard doses of $\mathrm{H}_{2}$ receptor blockers (cimetidine $(1 \cdot 2 \mathrm{~g} /$ day) or ranitidine (300 $\mathrm{mg} /$ day) in divided doses) for another two months, with treatment extended for up to six months when symptoms were unremitting. After this period, and when no major clinical changes were noted, anti-reflux surgery was indicated. When patients responded to pharmacological treatment, the drugs were progressively tapered to minimal effective maintenance doses while follow up was continued. Conversely, drug treatment was scaled up when symptomatic relapses occurred. The patient's own assessment of satisfaction or dissatisfaction was the main determinant of treatment modifications.

During follow up the patients were evaluated clinically at regular intervals of one to six months, depending on the clinical state. At each visit symptoms, compliance with conservative treatment, and the consumption of medications were assessed; advice on dietary, posture, and other lifestyle changes was reinforced when necessary. Endoscopies were performed every six months in patients with erosive oesophagitis and at least once in those with non-erosive GORD.

\section{Methods}

The scoring system for heartburn, regurgitation, and dysphagia was established from 0 points (no symptoms) to 5 points (daily, severe, disabling symptoms). The maximum clinical score was thus 15 points. Endoscopic oesophagitis was graded as follows: 0 , none; I, erythema; II, nonconfluent erosions; III, confluent erosions or circumferential shallow ulcerations; IV, deep ulcer or stricture. Endoscopic pinch biopsies were obtained at least $3 \mathrm{~cm}$ above the cardia and evaluated histologically according to standard criteria.

Manometry to determine mean basal lower oesophageal sphincter pressure (LOSP) and peristaltic response to wet swallows were performed as described. ${ }^{15} \mathrm{~A}$ standard acid reflux test $^{16}$ without $\mathrm{HCl}$ loading was carried out at the end of the oesophageal motility study. In January 1984 this test was substituted by stationary 24 hour oesophageal $\mathrm{pH}$ monitoring, which was performed and interpreted as previously reported. ${ }^{17}$

The diagnosis of GORD was based on a positive result in at least two of the following tests: spontaneous reflux of barium during radiological studies, erosions or ulcerations of the oesophageal mucosa at endoscopy, microscopic oesophagitis on endoscopic biopsy specimens, LOSP $\leqslant 7 \mathrm{~mm} \mathrm{Hg}$ (mean -2 SD of our motility laboratory controls), ${ }^{15} \mathrm{pH}<4$ during a standard acid reflux test or abnormal reflux by $24 \mathrm{~h} \mathrm{pH}$ monitoring.

Because all patients completing the long term study had a follow up of at least six years, outcomes were evaluated at three and six years after entry. Six possible outcomes were defined: (1) no symptoms or occasional symptoms requiring antacids; (2) sustained remission with frequent consumption of antacids with or without domperidone alone; (3) seasonal symptoms requiring full courses of treatment with either antacids or $\mathrm{H}_{2}$ blockers, with intervening periods as in outcomes 1 or 2 ; (4) sustained remission with daily maintenance doses of $\mathrm{H}_{2}$ blockers; (5) need of uninterrupted treatment with full dose $\mathrm{H}_{2}$ blockers; (6) anti-reflux procedure performed. To simplify the expression of results, outcomes 1 to 3 were grouped together as 'minor therapeutic need' (patients were comfortable most of the time utilising simple, inexpen-

TABLE I Results of diagnostic studies in 109 patients with reflux symptoms

\begin{tabular}{lll}
\hline Study & Diagnosis & No(\%) \\
\hline Barium swallow & Radiological reflux & $40(37)$ \\
Endoscopy & Erosive oesophagitis & $33(30)$ \\
Oesophageal biopsy & Microscopic oesophagitis & $97(89)$ \\
Motility studies & LOSP 57 mm Hg & $46(42)$ \\
SART $(\mathrm{n}=89)$ & Positive acid reflux & $25(28)$ \\
$\begin{array}{l}24 \text { hour pH monitoring } \\
(\mathrm{n}=20)\end{array}$ & Abnormal reflux & $18(90)$ \\
\hline
\end{tabular}

^Standard acid reflux test without $\mathrm{HCl}$ loading. 
sive therapeutic measures), whereas those labelled 4 to 6 were pooled as 'major therapeutic need' (patients required expensive pharmacological measures, close medical supervision, or surgery).

\section{EXPRESSION OF RESULTS AND STATISTICAL ANALYSES}

All quantitative data are expressed as means (SD). The unpaired Student's $t$ test, the nonparametric test of Mann-Whitney, an analysis of variance (ANOVA), and the $\chi^{2}$ test with continuity correction factor as needed were used when appropriate to detect any differences between groups. Statistical significance was defined at an $\alpha$ risk of $5 \%(p<0 \cdot 05)$. Multivariate statistics following Cox's logistic regression model ${ }^{18}$ was used to detect variables with predictive value; therapeutic need at three years was the dependent variable and all variables with predictive value by univariate analysis were included as independent variables. The statistical processing of the data for the multivariate analysis was performed with BMDP software. ${ }^{19}$

\section{Results}

FINDINGS AT INITIAL EVALUATION

Of the 132 patients initially evaluated, 23 were excluded for various reasons - namely, gastroduodenal ulcer found at barium studies or endoscopy (11), refusal to undergo one or more of the required procedures (seven), and negative results of oesophageal examinations (five patients). Thus 109 patients were finally included in the study ( 56 women and 53 men; age 50 (13), range 19-77 years).

Twenty seven $(25 \%)$ patients were cigarette smokers and 35 (32\%) were obese (body mass index >130). Heartburn was present in 106 (97\%), regurgitation in $90(82 \%)$, and dysphagia in $42(38 \%)$. Fifty nine $(54 \%)$ patients had nocturnal symptoms (heartburn or regurgitation awakening them from sleep) at least once a week. The mean clinical score was $6.4(2 \cdot 7)$ (range 3-13). A history of relapsing chest pain with negative cardiac studies was elicited from 21 (19\%) patients, whereas 37 (34\%) gave a history of bronchial asthma or chronic cough.

Table I gives the relevant results of oesophageal studies. The barium swallow revealed a hiatus hernia in 64 patients $(60 \%)$. The endoscopic grading of oesophagitis was 0,54 patients; I, 22 patients; II, 16 patients; III, six patients;

TABLE II Response to initial graded treatment in 107 patients with GORD in relation to presenting features

\begin{tabular}{llll}
\hline & $\begin{array}{l}\text { Control with } \\
\text { antacids } \\
(n=35)\end{array}$ & $\begin{array}{l}\text { Control with } \\
H_{2} \text { blockers } \\
(n=37)\end{array}$ & $\begin{array}{l}\text { Surgery } \\
\text { indicated } \\
(n=35)\end{array}$ \\
\hline Sex (F/M) & $19 / 16$ & $18 / 19$ & $19 / 16$ \\
Age (mean (SD) y) & $50(13)$ & $50(14)$ & $50(13)$ \\
Clinical score (mean (SD)) & $6 \cdot 2(2 \cdot 9)$ & $5 \cdot 9(2 \cdot 2)$ & $7 \cdot 1(2 \cdot 9)$ \\
Radiological reflux (No(\%)) & $13(37)$ & $8(22)$ & $19(54)^{\star}$ \\
Erosive oesophagitis (No(\%)) & $5(14)$ & $12(32)$ & $16(46) \dagger$ \\
LOSP(mean (SD) mm Hg) & $12 \cdot 3(7 \cdot 0)$ & $11 \cdot 1(6 \cdot 8)$ & $7 \cdot 0(4 \cdot 9) \ddagger$ \\
\hline
\end{tabular}

${ }^{\star} \mathrm{p}=0.009 v \mathrm{H}_{2}$ blocker group; $\mathrm{tp}=0.004 v$ antacid group; $\neq \mathrm{p}=0.001$ by analysis of variance. and IV, 11 patients (stricture, seven patients; deep ulcer, four patients, one of whom had Barrett's epithelium).

Symptom severity was unrelated to either the degree of endoscopic oesophagitis or to LOSP. On the other hand, 20 of 33 (61\%) patients with erosive oesophagitis had a basal LOSP $\leqslant 7 \mathrm{~mm}$ $\mathrm{Hg}$ whereas only 27 of 76 (36\%) with non-erosive GORD had abnormally low values $(p=0 \cdot 015)$.

\section{RESULTS OF INITIAL, GRADED TREATMENT}

Two patients voluntarily withdrew before completing the initial phase of medical treatment. Table II shows the response to treatment in relation to the clinical score, the presence of oesophagitis, and LOSP in the remaining 107 patients. About two thirds of the patients responded well to medical treatment; nearly half of them were well controlled with simple prokinetic plus antacid treatment, whereas the other half required addition of $\mathrm{H}_{2}$ blockers. Age, sex, smoking, obesity, and other clinical variables were unrelated to outcome. Whereas initial symptom severity did not predict the response, patients refractory to treatment were more likely to have both erosive oesophagitis and a lower LOSP than those with a good response (Table II). Among the non-responders there were 16 of $33(49 \%)$ patients with erosive oesophagitis, 22 of 45 (49\%) with LOSP $\leqslant 7 \mathrm{~mm} \mathrm{Hg}$, and 12 of 19 (63\%) with both abnormalities.

\section{OUTCOMES DURING FOLLOW UP}

The follow up time for the 107 patients completing the initial treatment phase is close to seven years (83 (30), range 6-136 months).

\section{Withdrawals and deaths}

Four patients (three deaths) were lost to follow up during the first three years, 12 additional patients withdrew from the study between the third and sixth year, and two deaths occurred during this period. All deaths were unrelated to GORD.

\section{Side effects of medical treatment}

Raising the head of the bed caused some problems for 12 patients. Eight of them repeatedly slipped off the end of the bed during the night; these difficulties were overcome by substituting cotton or wool garments for the original silk or nylon ones. Four patients had impaired venous circulation in the lower extremities and required an additional leg raising device for the night. Domperidone was universally well tolerated. Changes in bowel motions (either diarrhoea or constipation) attributable to antacid use were reported by 11 patients; they were solved by judicious substitution of equivalent aluminium hydroxide or magnesium hydroxide preparations for some of the doses of the original mixture. A 79 year old woman with borderline impaired renal function developed reversible, high output renal failure four weeks after starting treatment with $1200 \mathrm{mg}$ cimetidine a day. No side effects occurred with ranitidine. 
TABLE III Clinical state of 107 patients with GORD after long term follow up

\begin{tabular}{|c|c|c|}
\hline Treatment needs & $\begin{array}{l}\text { At } 3 \text { years } \\
(\mathrm{No}(\%))\end{array}$ & $\begin{array}{l}\text { At } 6 \text { years } \\
(\text { No }(\%))\end{array}$ \\
\hline $\begin{array}{l}\text { Well with conservative treatment: } \\
\text { Symptom free or occasional AA } \\
\text { Frequent use of AA } \\
\text { Seasonal AA or anti-H } \mathrm{H}_{2}\end{array}$ & $\begin{array}{l}17(16 \cdot 5) \\
21(20 \cdot 4) \\
16(15 \cdot 5)\end{array}$ & $\begin{array}{l}20(22 \cdot 5) \\
15(16 \cdot 9) \\
14(15 \cdot 7)\end{array}$ \\
\hline $\begin{array}{l}\text { Continuous treatment required: } \\
\text { Maintenance anti- } \mathrm{H}_{2} \\
\text { Full/scaled up anti- } \mathrm{H}_{2} \text { doses } \\
\text { Antireflux surgery }\end{array}$ & $\begin{array}{r}17(16 \cdot 5) \\
9(8 \cdot 7)^{\star} \\
23(22 \cdot 3)\end{array}$ & $\begin{array}{r}10(11 \cdot 2) \\
7(7 \cdot 9) \dagger \\
23(25 \cdot 8)\end{array}$ \\
\hline Total $\ddagger$ & $103(96 \cdot 3) \S$ & $89(83 \cdot 2)$ \\
\hline
\end{tabular}

${ }^{\star}$ Four patients required ranitidine $(600 \mathrm{mg} /$ day $)$ for proper control; ffour patients required omeprazole $(20 \mathrm{mg} /$ day) for good control; łnumber of patients available at each follow up period; percentage of patients completing the initial treatment protocol $(n=107) ; A A=$ antacids; anti- $H_{2}=$ histamine $H_{2}$ blockers.

\section{Anti-reflux surgery}

Anti-reflux surgery was eventually carried out in 23 of $35(66 \%)$ patients not responding to initial medical treatment, including 13 of 33 (39\%) patients and 10 of 74 (14\%) patients with and without oesophagitis, respectively. The reasons for not operating on the remaining 12 patients with refractory GORD were patient's refusal $(n=10)$ and high surgical risk $(n=2)$. A Nissen fundoplication was performed in 21 patients, whereas in the other two patients an antrectomy and $\mathrm{Y}$ de Roux procedure was selected as the surgical technique of choice because of the existence of a peptic stricture with shortened oesophagus. All surgical repairs were performed within the first three years (14 (6), range 3-24 months) after the initial evaluation.

\section{Long term outcome}

Whereas two thirds of the patients had initially required $\mathrm{H}_{2}$ blockers, $52 \%$ and $55 \%$ of those available for follow up at three and six years, respectively, fared well with a conservative approach (Table III). Anti-reflux surgery resulted in long lasting remission of reflux symptoms in 22 of 23 patients who were operated on and who have been followed up for 72 (15), range 54-116 months.

Table IV shows the treatment needs during long term follow up in relation to the outcome of initial, graded treatment. Nearly all patients who had a good initial response to domperidone plus antacids were well controlled with conservative measures at three and six years, and the same applied to nearly two thirds of those who had required $\mathrm{H}_{2}$ blockers at the outset.

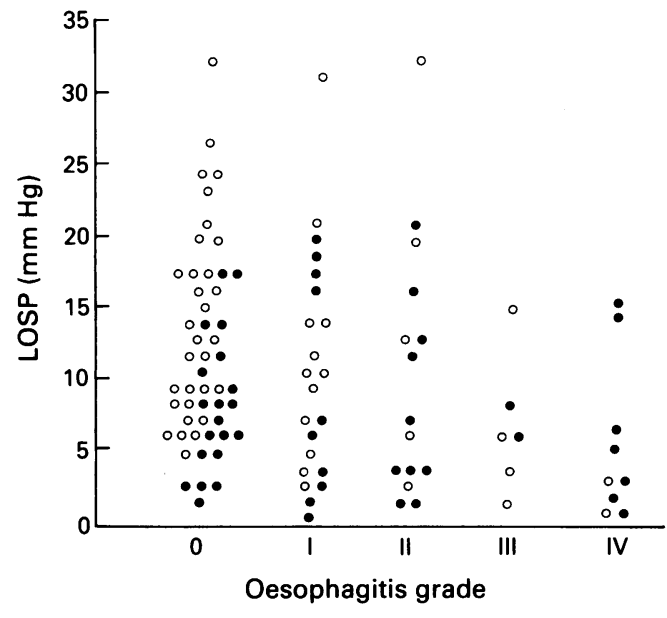

Relation of lower oesophageal sphincter pressure (LOSP) to the endoscopic grading of oesophagitis in 103 patients with gastro-oesophageal reflux disease divided into two groups with different treatment requirements after a follow up of three years: open circles, well with conservative treatment; closed circles, needing daily $\mathrm{H}_{2}$-blockers or anti-reflux surgery.

Long term treatment needs differed in patients with or without oesophagitis at entry (Table V). It is worth noting that one third of the patients with oesophagitis had a prolonged clinical remission with conservative measures alone, whereas slightly more than one third of those with non-erosive GORD needed more aggressive treatment for appropriate long term control.

Oesophagitis was healed at follow up endoscopy in the 13 patients operated on and in 10 medically treated patients; minimal oesophageal erosions remained for periods of up to two years in seven other patients who were otherwise in clinical remission with maintenance treatment. Follow up endoscopies in patients who entered the study without erosive oesophagitis showed normal oesophageal mucosa in all but two patients out of 73 available at three years and 63 at six years.

\section{Predictive factors}

Because patients with worse GORD underwent anti-reflux surgery early after entry and, except for a single patient with surgical failure, they were no longer under active treatment beyond three years, the analysis of possible predictive factors of outcome has been performed considering the clinical state of the patients at the three year assessment.

TABLE IV Treatment requirements for symptom control of patients with GORD during follow up according to the response to initial treatment

\begin{tabular}{|c|c|c|c|c|c|c|c|c|}
\hline \multirow[b]{3}{*}{ Response to initial treatment } & \multicolumn{8}{|c|}{ Treatment requirements } \\
\hline & \multicolumn{4}{|l|}{ At 3 years } & \multicolumn{4}{|l|}{ At 6 years } \\
\hline & Antacids $^{\star}$ & $A n t i-H_{2} f$ & Operated & Lost & Antacids $^{\star}$ & Anti- $\mathrm{H}_{2} t$ & Operated $\neq$ & Lost \\
\hline $\begin{array}{l}\text { Antacids }(n=35) \\
H_{2} \text { blockers }(n=37) \\
\text { Refractory to treatment }(n=35)\end{array}$ & $\begin{array}{l}28(85) \\
23(64) \\
3(9)\end{array}$ & $\begin{array}{c}3(9) \\
11(30) \\
12(35)\end{array}$ & $\begin{array}{l}2(6) \\
2(6) \\
19(56)\end{array}$ & $\begin{array}{l}2 \\
1 \\
1\end{array}$ & $\begin{array}{l}24(80) \\
20(66 \cdot 5) \\
5(17)\end{array}$ & $\begin{array}{l}4(13) \\
8(26 \cdot 5) \\
5(17)\end{array}$ & $\begin{array}{l}2(7) \\
2(7) \\
19(66)\end{array}$ & $\begin{array}{l}5 \\
7 \\
6\end{array}$ \\
\hline Total $(n=107)$ & $54(53)$ & $26(25)$ & $23(22)$ & 4 & $49(55)$ & $17(19)$ & $23(26)$ & 18 \\
\hline
\end{tabular}


TABLE V Treatment requirements during follow up according to the presence or absence of oesophagitis at the outset

\begin{tabular}{|c|c|c|c|c|c|c|c|c|}
\hline \multirow[b]{3}{*}{ Erosive oesophagitis } & \multicolumn{8}{|c|}{ Treatment requirements } \\
\hline & \multicolumn{4}{|l|}{ At 3 years } & \multicolumn{4}{|l|}{ At 6 years } \\
\hline & Antacids ${ }^{\star}$ & $A n t i-H_{2} t$ & Operated & Lost & Antacids ${ }^{\star}$ & Anti- $H_{2} t$ & Operated $\ddagger$ & Lost \\
\hline $\begin{array}{l}\text { Yes }(n=33) \\
\text { No }(n=74)\end{array}$ & $\begin{array}{l}11(37) \\
44(60)\end{array}$ & $\begin{array}{r}7(20) \\
19(26)\end{array}$ & $\begin{array}{l}13(43) \\
10(14)\end{array}$ & $\begin{array}{l}3 \\
1\end{array}$ & $\begin{array}{r}9(35) \\
40(64)\end{array}$ & $\begin{array}{r}4(15) \\
13(20)\end{array}$ & $\begin{array}{l}13(50) \\
10(16)\end{array}$ & $\begin{array}{r}4 \\
11\end{array}$ \\
\hline
\end{tabular}

Footnotes as for Table IV.

The relation of initial oesophagitis grade and basal LOSP with three year therapeutic need for each patient (Figure) shows that both oesophagitis and low LOSP are good predictors of outcome. Thus major treatment was required by 19 of 30 patients with and 30 of 73 without oesophagitis ( $p=0.040$ ), and by 28 of 45 patients with LOSP $\leqslant 7 \mathrm{~mm} \mathrm{Hg}$ and 21 of 58 with normal $\operatorname{LOSP}(p=0.009)$. The comparison of presenting features of patients with different treatment requirements at the three year evaluation (Table VI) also shows that oesophagitis and low LOSP, in addition to radiological reflux, were associated with major therapeutic need.

By multivariate analysis, the following factors were shown to be independent predictors of vigorous treatment requirements: low LOSP $(\mathrm{p}<0.001)$, radiological reflux $(\mathrm{p}=0.028)$, and erosive oesophagitis $(p=0.031)$. Respective positive predictive values, derived from data in Table V and the Figure, were $0.62,0.63$, and 0.63 .

\section{Discussion}

In this study 107 consecutive outpatients with documented GORD were prospectively evaluated with a clinical score, radiology, endoscopy, and manometry. They were subsequently managed with lifestyle changes plus a stepwise therapeutic approach and followed up for up to six years. Patient's satisfaction was the main factor that influenced treatment adjustments; thus the success of treatment (symptomatic remission) was determined by the patients rather than by their physicians. The results show that a conservative approach can provide long lasting remission in many patients and suggest that, once those with worse GORD are treated with anti-reflux surgery, the disease tends to run a

TABLE VI Presenting features of patients with GORD in relation to treatment requirements at three years

\begin{tabular}{|c|c|c|c|}
\hline Initial features & $\begin{array}{l}\text { Conservative } \\
\text { treatment }\end{array}$ & $\begin{array}{l}\text { Continuous } \\
\text { anti- } \mathrm{H}_{2} \text { or } \\
\text { anti-reflux } \\
\text { surgery }\end{array}$ & $p$ Value \\
\hline $\begin{array}{l}\text { Patients (No) } \\
\text { Sex }(M / F) \\
\text { Age (mean (SD) y) } \\
\text { Smokers (No) } \\
\text { Quit smoking (No (\%)) } \\
\text { Obese (No) } \\
\text { Lost >5 kg (No (\%)) } \\
\text { Clinical score (mean (SD)) } \\
\text { Hiatus hernia (No (\%)) } \\
\text { Radiological reflux (No (\%)) } \\
\text { Erosive oesophagitis (No (\%)) } \\
\text { LOSP (mean (SD) mm Hg) } \\
\text { Stimultaneous peristaltic waves }(\mathrm{No}(\%)) \\
\text { Distal peristaltic amplitude (mean (SD) mm Hg) } \\
\text { Distal amplitude < } 25 \text { mm Hg }(\mathrm{No}(\%))\end{array}$ & $\begin{array}{l}54 \\
27 / 27 \\
48(19) \\
17 \\
9(53) \\
17 \\
8(47) \\
6 \cdot 1(2 \cdot 7) \\
31(57) \\
14(26) \\
11(20) \\
12 \cdot 0(7 \cdot 1) \\
6(11) \\
43 \cdot 3(15 \cdot 6) \\
7(13)\end{array}$ & $\begin{array}{l}49 \\
23 / 26 \\
52(18) \\
10 \\
1(10) \\
18 \\
4(22) \\
6 \cdot 7(2 \cdot 7) \\
30(61) \\
24(49) \\
19(39) \\
7 \cdot 7(5 \cdot 0) \\
10(20) \\
40 \cdot 2(13 \cdot 2) \\
6(12)\end{array}$ & $\begin{array}{r}0.016 \\
0.040 \\
<0.001\end{array}$ \\
\hline
\end{tabular}

benign course; they also indicate that oesophagitis, radiological reflux, and low LOSP are independent predictors of more vigorous therapeutic need during long term follow up.

Because admission into the study was based on symptoms and not oesophagitis or abnormal prolonged $\mathrm{pH}$ monitoring, it could be argued that some patients were not true refluxers. Most patients with typical reflux symptoms can be diagnosed reliably, however, by history alone. ${ }^{20}$ Furthermore, each patient was positive in at least two of several highly specific tests for GORD.21 Most patients were studied before the widespread availability of 24 hour oesophageal pH monitoring; in the few patients in whom it was used, its positivity had a $90 \%$ correlation with symptoms. This test, however, has not yet been established as the gold standard for the diagnosis of GORD. ${ }^{22-24}$ Our patients had clinically severe GORD, as shown by the frequency of nocturnal reflux, respiratory symptoms, and non-cardiac chest pain, but only $30 \%$ had erosive oesophagitis and $10 \%$ had complications (strictures or deep oesophageal ulcer); on the other hand, clinical scores were similar regardless of oesophagitis grade. These findings underline the well known discrepancy between symptomatic severity and the endoscopic appearance of oesophagitis in GORD.

Whereas the clinical, endoscopic, and manometric scores of the patients who were refractory to medical treatment implied severe GORD, anti-reflux surgery had excellent results in 22 of 23 patients followed up for a mean of six years after the procedure. It deserves mention that these overall good surgical results were obtained by two surgeons (LG and CP) skilled in the technique of fundoplication. Reports on the long term follow up of patients whose surgical repair was performed by single surgical teams confirm the long lasting good results of this anti-reflux procedure. ${ }^{425} 26$

Although neither the clinical severity of GORD nor the presence of oesophagitis seem to be related to increased rates of gastric acid secretion, ${ }^{2728}$ it is clear now that profound acid suppression, such as that provided by the drug omeprazole, is required for symptom control and healing of oesophagitis in many patients..$^{99}$ Had our study not predated the availability of omeprazole, some patients might not have been submitted to anti-reflux surgery because of refractory GORD.

Due to the tendency of GORD to improve during extended outpatient care (table IV), the initial response to graded treatment was a good predictor of treatment needs during long term follow up only for patients achieving symptomatic remission with conservative treatment. 
Thus $80 \%$ of those and $67 \%$ of patients initially requiring $\mathrm{H}_{2}$ blockers had a lasting response to simple modes of treatment, which was shared by $17 \%$ of the patients who had been refractory to short term medical management but did not have anti-reflux surgery. The results challenge the presumption that long term intensive treatment is necessary for most patients with GORD. Other authors ${ }^{7-10}$ have reported that patients with oesophagitis relapse quickly when pharmacological treatment is interrupted. Both selection of more severe cases and the overlooking of lifestyle modifications in these studies ${ }^{7-10}$ could explain the differences from our present series.

At all times during prolonged patient care in our study emphasis was placed on simplistic, traditional modes of treatment, such as diet modification, elevation of the bedhead, tobacco, alcohol and drug restriction, and antacid use. As recently reviewed, ${ }^{30}$ these measures are based on sound physiological principles but are often neglected in this age of potent acid suppressive drugs. In our study controllable changes, like stopping smoking and weight loss, occurred more often in patients who did well on conservative treatment (Table VI).

Little is known about factors influencing therapeutic responses in GORD. ${ }^{729} \mathrm{We}$ did not carry out tests for alkaline reflux, which can be associated with complications of oesophagitis or refractoriness to medical treatment. ${ }^{31}$ The logistic regression analysis in our study shows that a low basal LOSP, the detection of reflux by barium meal, and the existence of oesophageal erosions as judged by endoscopy, independently predict the long term need for sustained pharmacological acid suppression or anti-reflux surgery in GORD. According to their positive predictive values, the presence of each one of these variables would correctly predict the long term course in roughly two out of every three patients, thus their investigation should be clinically useful. The association of low LOSP with vigorous long term treatment requirements is consistent with available evidence. ${ }^{1121273233}$ A potential explanation for the fact that radiological reflux had prognostic value independently of LOSP could be that, as well as a low basal LOSP, it reflected an increased rate of transient relaxations of a normotensive lower oesophageal sphincter after the barium meal. ${ }^{34}$ As expected, ${ }^{72}$ another independent predictor of need for continuous treatment was the presence of endoscopic oesophagitis at initial evaluation. Taken together, these results suggest that refractoriness to conservative treatment in GORD is due to the severity of the reflux itself.

For such a common disease as GORD, it is surprising how little is known about the long term outcome of treated patients. Studies of patients with oesophagitis followed up for periods of two to three years under continuous treatment with antacids ${ }^{32}$ or $\mathrm{H}_{2}$ blockers with or without added metoclopramide" indicate that a significant proportion of patients have frequent symptomatic relapses when treatment is tapered off. On the other hand, continuous treatment of patients with complicated GORD with a combination of general anti-reflux measures, antacids, and standard doses of ranitidine is useful in controlling symptoms for up to two years, although surgical treatment is more effective. ${ }^{35} \mathrm{~A}$ recent study suggests that most patients with non-erosive GORD treated with antacids, but not advised on lifestyle changes, have persisting symptoms after one year. ${ }^{36}$ Schindlbeck et $a l^{37}$ have recently reported that less than a quarter of patients with conventional GORD treated conservatively improve after three years; these patients, however, were not directly followed up by the authors after diagnosis, and no mention is made of modifications in lifestyle. ${ }^{37} \mathrm{~A}$ different picture emerges from our study, which shows that more than half of unselected patients with GORD do well with simple modes of treatment for up to six years. Consequently, the clinical course of GORD under continuous medical surveillance seems to be more benign than previously presumed.

The clinical experience gained in this study supports the notion that conservative treatment should be tried initially in patients with reflux symptoms. ${ }^{32130}$ Many patients will be expected to have a lasting response to this simple, low cost approach. In non-responding patients, radiological, endoscopic, and manometric findings have predictive value for the long term outcome and can help in the early selection of candidates for anti-reflux surgery or, alternatively, sustained pharmacological acid suppression.

This work was supported in part by grants $85 / 1130$ and $90 / 0505$ from FIS, Spanish Ministry of Health, a grant of the Hospital Clínic i Provincial to Dr A Pujol, and the Fundació Catalana per l'Estudi de les Malaltíes del Fetge i Gastroenterologiques.

1 Gallup Organisation. Heartburn across America: a Gallup Organisation survey. Princeton: Gallup Organisation, 1988.

2 Graham DY, Smith JL, Patterson DJ. Why do apparently healthy people use antacid tablets? Am f Gastroenterol 1983; 78: $257-60$.

3 Castell DO. Overview of treatment of gastroesophageal reflux disease. In: Castell DO, Wu WC, Ott DJ, eds. Gastroesophageal reflux disease: pathogenesis, diagnosis, therapy. Mount Kisco, NY: Futura, 1985: 211-20.

4 Dehn TCB. Surgery for uncomplicated gastrooesophagea reflux. Gut 1992; 33: 293-4.

5 Heading RC. Epidemiology of oesophageal reflux disease. Scand F Gastroenterol 1989; 24 (suppl 168): 33-7.

6 Koelz HR. Treatment of reflux esophagitis with $\mathrm{H}_{2}$-blockers, antacids and prokinetic drugs: an analysis of randomized clinical trials. Scand f Gastroenterol 1989;24 (suppl 156): 25clinica.

7 Koelz HR, Birchler R, Bretholz A, Bron B, Capitaine Y, Delmore $\mathrm{G}$, et al. Healing and relapse of reflux oesophagitis during treatment with ranitidine. Gastroenterology 1986; 91 1198-205.

8 Sandmark S, Carlsson R, Fausa O, Lundell L. Omeprazole or ranitidine in the treatment of reflux esophagitis. Results of a double-blind, randomized, Scandinavian multicenter study. Scand f Gastroenterol 1988; 23: 625-32.

9 Glise H. Healing, relapse rates and prophylaxis of reflux esophagitis. Scand $\mathcal{F}$ Gastroenterol 1989; 24 (suppl 156): 5764.

10 Tytgat GNJ. Drug therapy of reflux oesophagitis: an update. Scand f Gastroenterol 1989; 24 (suppl 168): 38-49.

11 Lieberman D. Medical therapy for chronic reflux esophagitis Long-term follow-up. Arch Intern Med 1987; 147: 1717-20.

12 Price SF, Smithson KW, Castell DO. Food sensitivity in reflux esophagitis. Gastroenterology 1978; 75: 240-3.

13 Kjellen G, Tibbling L. Influence of body position, dry and water swallows, smoking, and alcohol on esophageal acid clearing. Scand F Gastroenterol 1978; 13: 283-8.

14 Richter JE, Castell DO. Drugs, foods, and other substances in the cause and treatment of reflux esophagitis. Med Clin North Am 1981; 65: 1223-34.

15 Ros E, Pujol A, Bordas JM, Grande L. Efficacy of sucralfate in refractory reflux esophagitis. Results of a pilot study. Scand f Gastroenterol 1989; 24 (suppl 156): 49-55.

16 Skinner DB, Booth DJ. Assessment of distal esophageal function in patients with hiatal hernia and/or gastrofunction in patients with hiatal hernia an

17 Pujol A, Grande L, Ros E, Pera C. Utility of inpatient 24-hour intraesophageal $\mathrm{pH}$ monitoring in diagnosis of gastrointraesophageal pH monitoring in diagnosis

18 Cox DR. Regression models and life tables. Fournal of the Royal Statistical Society 1972; 34: 187-220.

19 Dixon WJ. BMDP Statistical Software. Berkeley: University of California Press, 1983. 
20 Klauser AG, Schindlbeck NE, Müller-Lissner SA. Symptoms in gastro-oesophageal reflux disease. Lancet 1990; 335: $205-8$.

21 Richter JE, Castell DO. Gastroesophageal reflux. Pathogenesis, diagnosis, and therapy. Ann Intern Med 1982; 97: 93-103.

22 Tytgat GNJ, Bennett JR, Dent J, Joelsson B. Oesophageal pH monitoring - normal and abnormal. Gastroenterology International 1989; 3: 141-9.

23 Castell DO. pH monitoring versus other tests for gastroesophageal reflux disease: is this the gold standard? In: Richter JE, ed. Ambulatory esophageal pH monitoring. New York: Igaku-Shoin, 1991: 101-13.

24 Grande L, Culell P, Ros E, Lacima G, Pujol A, GarcíaValdecasas JC, et al. Comparison of stationary vs ambulatory 24-hour $\mathrm{pH}$ monitoring systems in diagnosis of gastroesophageal reflux disease. Dig Dis Sci 1993; 38: 213-9.

25 Negre JB, Markkula HT, Keyrilainen P. Nissen fundoplication. Results at 10 year follow-up. Am $\mathcal{F}$ Surg 1983; 146: 635-8.

26 DeMeester TR, Bonavina L, Albertucci M. Nissen fundoplication for gastroesophageal reflux disease. Evaluation of primary repair in 100 consecutive patients. Ann Surg 1986; 204: 9-20.

27 Barlow AP, DeMeester TR, Ball CS, Eypasch EP. The significance of the gastric secretory state in gastroesophageal significance of the gastric secretory state in gast
reflux disease. Arch Surg 1989; 124: 937-40.

28 Hirschowitz BI. A critical analysis, with appropriate controls, of gastric acid and pepsin secretion in clinical esophagitis. of gastric acid and pepsin secretion in

29 Hetzel DJ, Dent J, Reed WD, Narielvala FM, Mackinnon M,
McCarthy $\mathrm{JH}$, et al. Healing and relapse of severe peptic esophagitis after treatment with omeprazole. Gastroenterology 1988; 95: 903-12.

$30 \mathrm{Kitchin} \mathrm{LI,} \mathrm{Castell} \mathrm{DO.} \mathrm{Rationale} \mathrm{and} \mathrm{efficacy} \mathrm{of} \mathrm{conservative}$ therapy for gastroesophageal reflux. Arch Intern Med 1991; 151: 448-54.

31 Clark GWB, Hinder RA. Alkaline gastroesophageal reflux. In: Richter JE, ed. Ambulatory esophageal pH monitoring. New York: Igaku-Shoin, 1991: 209-24.

32 Behar J, Sheahan DG, Biancani P. Medical and surgical management of reflux esophagitis. A 38-month report on a management of reflux esophagitis. A 38-month report on

33 Saco LS, Orlando RC, Levinson SL, Bozymsky EM, Jones JD, Frakes JT. Double-blind controlled trial of bethanecol and antacid in the treatment of erosive esophagitis. Gastroand antacid in the treatment

34 Holloway RH, Kocyan P, Dent J. Provocation of transient lower esophageal sphincter relaxations by meals in patients with symptomatic gastroesophageal reflux. Dig Dis Sci 1991; 36: 1034-9.

35 Spechler SJ, and the Department of Veterans Affairs Gastroesophageal Reflux Disease Study Group. Comparison of medical and surgical therapy for complicated gastroesophageal reflux disease in veterans. $N$ Engl $7 \mathrm{Med} 1992$; 326: 78692 .

36 Pace F, Santalucia F, Bianchi Porro G. Natural history of gastro-oesophageal reflux disease without oesophagitis. Gut gastro-oesophage

37 Schindlbeck NE, Klauser AG, Beghammer G, Londong W, Müller-Lissner SA. Three year follow up of patients with Müller-Lissner SA. Three year follow up of patients with
gastro-oesophageal reflux disease. Gut 1992; 33: 1016-9. 